\title{
Can the Interspinous Distance Predict Kyphosis in Conservative Treatment in Thoracolumbar Burst Fracture? A Retrospective, Diagnostic Study
}

\author{
Robert Meves*, Osmar Avanzi \\ Orthopedics Department, Faculty of Medical Sciences, Santa Casa Spine Center, São Paulo, Brazil \\ Email: "robertmeves@hotmail.com
}

Received 23 November 2015; accepted 22 January 2016; published 25 January 2016

Copyright $@ 2016$ by authors and Scientific Research Publishing Inc.

This work is licensed under the Creative Commons Attribution International License (CC BY). http://creativecommons.org/licenses/by/4.0/

(c) (i) Open Access

\begin{abstract}
Study Design: Retrospective, diagnostic study. Objective: To verify if the interspinous distance is able to predict the risk for kyphotic collapse in thoracolumbar burst fractures treated conservatively without neurological deficit. Summary of Background Data: In patients with thoracolumbar burst fractures, the association between the amount of comminution, by using load-sharing classification (LSC), and kyphotic collapse is presented in the literature. However, LSC does not include the interspinous distance as an indirect sign to suggest biomechanical instability due to posterior ligamentous disruption in these patients in order to predict kyphotic collapse. Methods: We added the interspinous distance to the load-sharing classification (MLSC) in 50 consecutive patients with thoracolumbar burst fractures (according to Denis criteria) treated conservatively. Results: The LSC score was correlated to kyphotic collapse in the patients treated with TLSO $(r=0.312, p=$ 0.027; Spearman test; $A=0.668$ ). The MLSC was similarly correlated to kyphotic collapse among TLSO-treated patients $(r=0.295, p=0.038$; Spearman test; $A=0.652)$. Conclusions: The interspinous distance did not contribute to the identification of worse radiographic outcomes, represented by the kyphotic collapse. This may suggest that the amount of comminution pointed out by the LSC is enough and more important than the interspinous opening in order to predict kyphotic collapse in thoracolumbar burst fractures. Possibly, the interspinous distance is much too heterogenous and multifactorial to be useful, since it reflects vertebral body height, preinjury anatomy, as well as posterior element disruption.
\end{abstract}

\section{Keywords}

Spine, Spinal Fractures, Trauma Severity Indices

\footnotetext{
${ }^{*}$ Corresponding author.
}

How to cite this paper: Meves, R. and Avanzi, O. (2016) Can the Interspinous Distance Predict Kyphosis in Conservative Treatment in Thoracolumbar Burst Fracture? A Retrospective, Diagnostic Study. Open Journal of Orthopedics, 6, 10-15. 


\section{Introduction}

The increasing incidence of spine injuries today inspires studies that help in the classification and treatment of patients with thoracolumbar fractures [1] [2]. This region accounts for the vast majority of fractures in the spine. Of all types of fractures in this region, burst fractures are the most studied, due to its high frequency and high morbidity in multiple trauma patients, even in those without neurological deficits [2]-[4].

Holdsworth [5], in 1970, classified the thoracolumbar fractures based on the model of two columns, divided by the anterior longitudinal ligament, and they also described the burst fracture as a secondary injury to the compressive rupture of the vertebral body after an axial load. Two decades later, Denis [6] introduced the concept of the three parts of the column: anterior, middle and posterior columns. A burst fracture was classified as a major spinal injury affecting the anterior and middle columns [5]-[7]. The Magerl classification [8] described the possibility, in these fractures, of posterior ligament injury associated with the retropulsed fragment into the spinal canal (B subtype). However, only the classification of McCormack et al. [7], known as the load sharing classification (LSC), suggests that the amount of comminution of the vertebral body can predict kyphotic collapse in these fractures [9]-[12].

Some authors have studied the ability of McCormack scoring system to predict kyphosis collapse after conservative treatment in thoracolumbar burst fractures [12]-[14]. In our view, there is a lack, in the scoring system proposed by McCormack, of variables addressing the increased interspinous distance as an indirect sign to suggest instability due to posterior ligamentous disruption in these patients. The most used method to investigate the posterior ligament insufficiency is the analysis of the opening of the spinous processes. Based on the anteriorposterior radiographic analysis of 200 normal subjects, Neumann et al. [15] defined the indirect values indicative of this failure that were accurate and reproducible among independent examiners. In clinical practice, most physicians believe that patients with increased interspinous distance have an indirect sign of biomechanical instability due to posterior spinal ligament insufficiency. We hope, therefore, to contribute to this discussion and present a complement of the LSC, adding the interspinous distance to the load-sharing classification (MLSC) to further studies.

\section{Materials and Methods}

This is a cohort, retrospective study, including all consecutive patients without neurological deficit admitted to a public, university, emergency hospital, between January 2000 and January 2012, with thoracolumbar burst fractures according to the Denis [6] criteria. Patients were treated with Jewet thoracolumbosacral orthosis (TLSO) [16]. They were all classified according to McCormack et al. [7] score and also with a new evaluation system proposed here, as described in details below, which includes the interspinous distance. The association of the two scores and failure of instrumentation and kyphosis deformity was searched. The study was approved by the local Ethics Committee. All patients underwent X-rays and computed tomography (CT) scans in the supine position. This is a retrospective study, based on the medical records of the patients. Therefore, the treatment with was according to the attending physician's at the time of admittance to the emergency room. To be included in this study, the lesion should have happened in the period of 10 days before hospital admittance. Patients were excluded if they had a follow-up period of less than six months. They were also excluded if they had lesions in more than one spine level, puncturing or gunshot traumas, if they had bone diseases. Since this is a study based on medical records, the patients with incomplete records or without imaging exams available for analysis were excluded.

The Cobb angles [17] were measured in the plain radiographs taken at admittance, after surgery or brace and at the final follow-up. Patients also underwent CT, with Tomoscan Philips 300, 350, CX/Q (AV, EG, Netherlands) equipment. Bone tissue was targeted, with a mean width window of 2000 - 3200 Hounsfield units and mean window level of 200 - 300 Hounsfield units, with 3 to 5 mm-thick axial sections perpendicularly oriented to the longitudinal axis of the fractured vertebra's vertebral canal and its adjacent levels. The narrowing of the spinal canal was calculated on the digital CT scans in percentages, considering the adjacent vertebrae (with no fracture) as normal references 3. LSC7 score has three categories, and for each of them a maximum of three points are assigned. The categories are: 1) degree of vertebral comminution in sagittal axis, 2) degree of posterior fragment displacement from the facture in axial CT, and 3) degree of kyphosis correction relative to the anatomic level. We propose a modified classification system in this study, adding the interspinous opening to the load-sharing classification, and creating the modified load sharing classification (MLSC). For the analysis of 
the posterior spinal process distance, we used the method proposed by Neumann et al. [15] which quantifies the opening of the spinal processes in the posterior vertebral arch in radiographs in anterior-posterior (AP) view, taking into consideration the cranial end of the base of the spinous processes. The averages in adjacent levels were used as standards for normality. The distance was measured taking the cranial end of the "tear-drop" image of the spinous process in AP view (Figure 1). An upper limit of a normal difference in distance between the spinous processes at two adjacent levels was determined, in the evaluation proposed here, to be $7-10 \mathrm{~mm}$. Based on this value, the severity of the opening was graded as 1,2 or 3 , with 1 point for openings between 0 and $6 \mathrm{~mm}, 2$ points for 7 to $9 \mathrm{~mm}$ and 3 points when $10 \mathrm{~mm}$ or over. These points were added to the LSC score, therefore the MLSC ranged from 4 to 12. Descriptive statistics of the data was made and to analyze the correlation between scores and Cobb angle of sagittal deformity, we used the Spearman correlation. We used ROC curves for patients with a loss equal to or greater than 10 degrees in order to define kyphotic collapse in these fractures during the follow-up. We considered the significance level of 5\%, and used the software SPSS (Statistical Package for Social Sciences), version 13.0 in the statistical analysis.

\section{Results}

Fifty patients completed the criteria of this study. .The LSC score was correlated to kyphosis deformity in the patients treated with TLSO $(r=0.312, p=0.027$; Spearman's test). The MLSC score was also correlated to kyphosis collapse among TLSO-treated patients $(\mathrm{r}=0.295) 11(22 \%)$ had a difference of $10^{\circ}$ or higher (kyphotic collapse) compared to pre-treatment measurement. The ROC curve in Figure 2 illustrates the similarity between the two scoring systems to predict a kyphosis of $10^{\circ}$ or higher (kyphotic collapse) in patients treated with brace (A $=0.668$ and $\mathrm{A}=0.652$ for LSC and MLSC, respectively).

\section{Discussion}

Thoracolumbar burst fractures are found in patients suffering from multiple injuries from high-energy traumas [11]. In these cases, detailed clinical and imaging exams are performed in search for parameters indicating injuries to the posterior capsular ligamentous complex [13] [14] [16]. The most used currently is the posterior interspinous opening [7]-[9]. It is interesting to note that, in practice, a lesion to the capsular ligamentous complex is suspected based on radiographic parameters according to the great majority of surgeons. Obviously, the ability to predict what fracture will deform would be of value to the clinician [18]-[21].

The signs on radiography and axial-CT that are characteristic of burst-type fractures described by Denis [6] were found by other authors [1] [11]-[17] [22]-[25] in injuries with flexion and distraction, since the mechanism of injury in these cases can aggregate axial forces that result in compression injury of the posterior column (sub type B of Margerl et al.) [8]. In burst fractures, injuries in the posterior capsular ligamentous complex may be

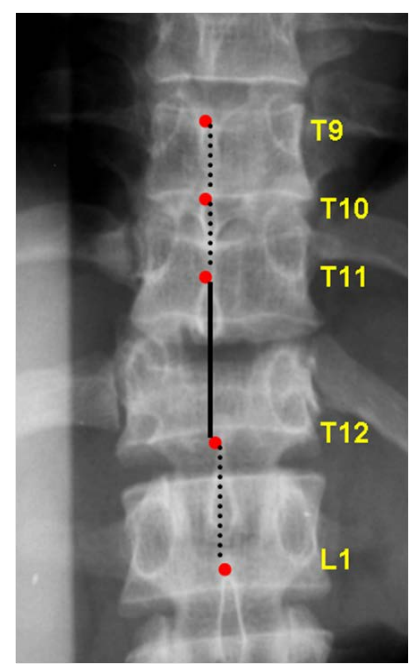

Figure 1. Neumann et al. [15] method for the measurement of interspinous distance. 
ROC Curve

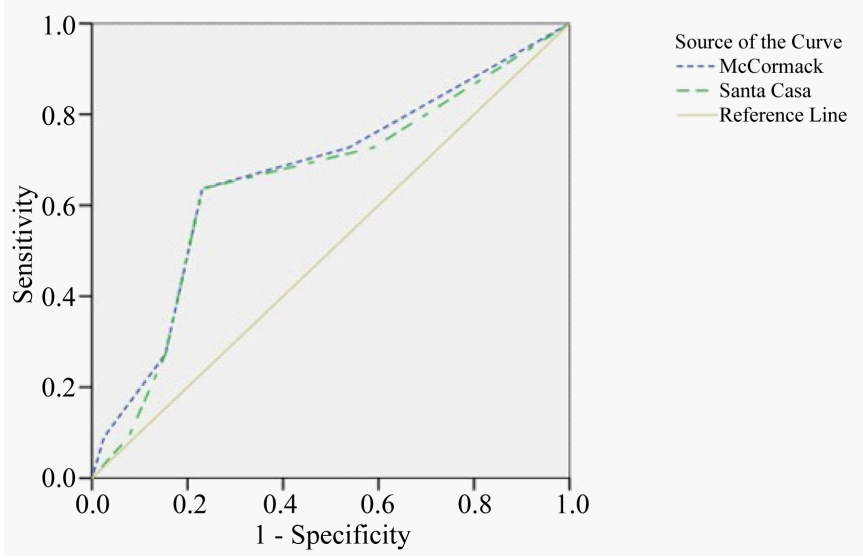

Figure 2. ROC (receiver operator characteristic) curve for the scores and kyphotic collapse in patients treated with brace. Dashed line shows the load sharing classification (LSC), and dotted line shows the modified load sharing classification proposed in this study (MLSC)

suggested by the increase in the interspinous distance at the level of fracture in AP plain radiographs [18]-[20].

The scoring system proposed here (MLSC) adds the possibility to consider the increase in the interspinous distance, which is not included in the LSC classification. In patients without this interspinous opening, magnetic resonance (MRI), although more sensitive and specific to ascertain the posterior ligament injury, was not associated with worse clinical outcomes and radiographic findings in these patients [20]. Another argument for not recommending routine MRI in these patients is the high cost of the test [18]-[20] [23] [24]. This could be very important in regions where the access to the MRI would be difficult or even impossible.

Similar to our study, the correlation between the kyphotic collapse and the LSC in patients treated conservatively is pointed out by other authors [12]. Although the MLSC has correlated with the kyphotic collapse in patients undergoing the conservative treatment, it did not increase the predictive power for kyphosis worsening compared with the LSC. This may suggest that the amount of comminution pointed out by the LSC is enough and more important than the interspinous opening in order to predict kyphotic collapse in thoracolumbar burst fractures. Possibly, the interspinous distance is much too heterogenous and multifactorial to be useful, since it reflects vertebral body height, preinjury anatomy, as well as posterior element disruption. At any rate, our results, even negative, must be looked at in future systematic review studies and MLSC considered in future prospective research.

We observed that the additional points referring to interspinous opening did not contribute to the identification of worst radiographic outcomes, represented by kyphotic collapse. We suggest studying the application of MLSC in patients with flexion-distracting (type B) and rotation (type C of Magerl) injuries.

\section{Conflict of Interest Statement}

None of the authors of the above manuscript has declared any conflict of which may arise from being named as an author on the manuscript.

\section{Disclosure}

Nothing to disclosure.

\section{References}

[1] Kim, N.H., Lee, H.M. and Chun, I.M. (1999) Neurologic Injury and Recovery in Patients with Burst Fracture of the Thoracolumbar Spine. Spine (Phila Pa 1976), 24, 290-293; Discussion 294. http://dx.doi.org/10.1097/00007632-199902010-00020

[2] Lee, G., Wang, Q., Zhong, D., et al. (2012) Relation between Injury Severity and Neurologic Deficit in Thoracolumbar 
Burst Fracture. Journal of Spinal Disorders \& Techniques. [Epub Ahead of Print] http://dx.doi.org/10.1097/BSD.0b013e3182779b9f

[3] Meves, R. and Avanzi, O. (2006) Correlation among Canal Compromise, Neurologic Deficit, and Injury Severity in Thoracolumbar Burst Fractures. Spine (Phila Pa 1976), 31, 2137-2141. http://dx.doi.org/10.1097/01.brs.0000231730.34754.9e

[4] Gertzbein, S.D. (1994) Spine Update. Classification of Thoracic and Lumbar Fractures. Spine (Phila Pa 1976), 19, 626-628. http://dx.doi.org/10.1097/00007632-199403000-00022

[5] Holdsworth, F. (1970) Fractures, Dislocations, and Fracture-Dislocations of the Spine. Journal of Bone \& Joint Surgery, American Volume, 52, 1534-1551.

[6] Denis, F. (1983) The Three Column Spine and Its Significance in the Classification of Acute Thoracolumbar Spinal Injuries. Spine (Phila Pa 1976), 8, 817-831. http://dx.doi.org/10.1097/00007632-198311000-00003

[7] McCormack, T., Karaikovic, E. and Gaines, R.W. (1994) The Load Sharing Classification of Spine Fractures. Spine (Phila Pa 1976), 19, 1741-1744. http://dx.doi.org/10.1097/00007632-199408000-00014

[8] Magerl, F., Aebi, M., Gertzbein, S.D., et al. (1994) A Comprehensive Classification of Thoracic and Lumbar Injuries. European Spine Journal, 3, 184-201. http://dx.doi.org/10.1007/BF02221591

[9] Parker, J.W., Lane, J.R., Karaikovic, E.E., et al. (2000) Successful Short-Segment Instrumentation and Fusion for Thoracolumbar Spine Fractures: A Consecutive 41/2-Year Series. Spine (Phila Pa 1976), 25, 1157-1170. http://dx.doi.org/10.1097/00007632-200005010-00018

[10] Aligizakis, A.C., Katonis, P.G., Sapkas, G., et al. (2003) Gertzbein and Load Sharing Classifications for Unstable Thoracolumbar Fractures. Clinical Orthopaedics and Related Research, 411, 77-85. http://dx.doi.org/10.1097/01.blo.0000068187.83581.5d

[11] Sar, C. and Bilen, F.E. (2002) Thoracolumbar Flexion-Distraction Injuries Combined with Vertebral Body Fractures. American Journal of Orthopedics (Belle Mead NJ), 31, 147-151.

[12] Aligizakis, A., Katonis, P., Stergiopoulos, K., et al. (2002) Functional Outcome of Burst Fractures of the Thoracolumbar Spine Managed Non-Operatively, with Early Ambulation, Evaluated Using the Load Sharing Classification. Acta Orthopcedica Belgica, 68, 279-287.

[13] Scholl, B.M., Theiss, S.M. and Kirkpatrick, J.S. (2006) Short Segment Fixation of Thoracolumbar Burst Fractures. Orthopedics, 29, 703-708.

[14] Konyves, A., Chiverton, N., Douglas, D.L., et al. (2010) Short-Segment Posterior Stabilisation and Fusion for Thoraco-Lumbar Burst Fractures. Journal of Bone and Joint Surgery British, 92-B, 377. http://www.bjjprocs.boneandjoint.org.uk/content/92-B/SUPP_III/377.4.short

[15] Neumann, P., Wang, Y., Kärrholm, J., et al. (1999) Determination of Inter-Spinous Process Distance in the Lumbar Spine. Evaluation of Reference Population to Facilitate Detection of Severe Trauma. European Spine Journal, 8, $272-$ 278. http://dx.doi.org/10.1007/s005860050172

[16] Frankel, H.C., Hancock, D.O., Hyslop, G., et al. (1969) The Value of Postural Reduction in the Initial Management of Closed Injuries of the Spine with Paraplegia and Tetraplegia. I. Paraplegia, 7, 179-192. http://dx.doi.org/10.1038/sc.1969.30

[17] Cobb, J.R. (1984) Outline for the Study of Scoliosis. In: Instructional Course Lectures. The American Academy of Orthopaedics Surgeons, 261-275.

[18] Vaccaro, A.R., Lee, J.Y., Schweitzer Jr., K.M., et al. (2006) Assessment of Injury to the Posterior Ligamentous Complex in Thoracolumbar Spine Trauma. Spine Journal, 6, 524-528. http://dx.doi.org/10.1016/j.spinee.2006.01.017

[19] Caffaro, M.F. and Avanzi, O. (2011) Is There a Difference between Narrowing of the Spinal Canal and Neurological Deficits Comparing Denis and Magerl Classifications? Spinal Cord, 49, 297-301. http://dx.doi.org/10.1038/sc.2010.112

[20] Vaccaro, A.R., Kim, D.H., Brodke, D.S., et al. (2003) Diagnosis and Management of Thoracolumbar Spine Fractures. The Journal of Bone \& Joint Surgery, 85, 2456 -2470.

[21] Machino, M., Yukawa, Y., Ito, K., Kanbara, S. and Kato, F. (2013) The Complement of the Load-Sharing Classification for the Thoracolumbar Injury Classification System in Managing Thoracolumbar Burst Fractures. Journal of Orthopaedic Science, 18, 81-86. http://dx.doi.org/10.1007/s00776-012-0319-4

[22] Trafton, P.G. and Boyd Jr., C.A. (1984) Computed Tomography of Thoracic and Lumbar Spine Injuries. Journal of Trauma, 24, 506-515. http://dx.doi.org/10.1097/00005373-198406000-00008

[23] Dai, L.Y., Ding, W.G., Wang, X.Y., et al. (2009) Assessment of Ligamentous Injury in Patients with Thoracolumbar Burst Fractures Using MRI. Journal of Trauma, 66, 1610-1615. http://dx.doi.org/10.1097/TA.0b013e3181848206

[24] Radcliff, K., Kepler, C.K., Rubin, T.A., et al. (2012) Does the Load-Sharing Classification Predict Ligamentous Injury, 
Neurological Injury, and the Need for Surgery in Patients with Thoracolumbar Burst Fractures? Clinical Article. Journal of Neurosurgery: Spine, 16, 534-538. http://dx.doi.org/10.3171/2012.3.SPINE11570

[25] Canbek, U., Karapınar, L., İmerci, A., et al. (2014) Posterior Fixation of Thoracolumbar Burst Fractures: Is It Possible to Protect One Segment in the Lumbar Region? European Journal of Orthopaedic Surgery \& Traumatology, 24, 459465. http://dx.doi.org/10.1007/s00590-013-1326-7 